\title{
Integral energy performance characterization of semi-transparent photovoltaic elements for building integration under real operation conditions
}

\author{
L. Olivieri , E. Caamaño-Martin , F .Olivieri , J. Neila
}

\begin{abstract}
A B S T R A C T
In this paper, a methodology for the integral energy performance characterization (thermal, daylighting and electrical behavior) of semi-transparent photovoltaic modules (STPV) under real operation conditions is presented. An outdoor testing facility to analyze simultaneously thermal, luminous and electrical performance of the devices has been designed, constructed and validated. The system, composed of three independent measurement subsystems, has been operated in Madrid with four prototypes of a-Si STPV modules, each one corresponding to a specific degree of transparency. The extensive experimental campaign, continued for a whole year rotating the modules under test, has validated the reliability of the testing facility under varying environmental conditions.

The thermal analyses show that both the solar protection and insulating properties of the laminated prototypes are lower than those achieved by a reference glazing whose characteristics are in accordance with the Spanish Technical Building Code. Daylighting analysis shows that STPV elements have an important lighting energy saving potential that could be exploited through their integration with strategies focused to reduce illuminance values in sunny conditions. Finally, the electrical tests show that the degree of transparency is not the most determining factor that affects the conversion efficiency.
\end{abstract}

\section{Introduction}

Building-integrated photovoltaics (BIPV) is one of the most promising technologies enabling buildings to generate part of their electricity needs while performing architectural functionalities $[1,2]$. A clear example is the use of semi-transparent photovoltaic modules (STPV) integrated in façade, where the active building envelope is required to perform multiple (and sometimes opposed) requirements such as perform as a solar shading in summer to avoid overheating, supply solar gains and thermal insulation in winter to reduce heat loads, provide daylight utilization to reduce lighting loads, allow the outside view to the occupants and supply maximum electrical output. In general, reducing the transparency degree in STPV modules reduces the solar heat gains and daylight availability. However, the electrical output can be improved due to the superior conversion efficiency of low transparency degree modules. Consequently, a balance should be archived between daylight use, thermal performance and power generation. To minimize the final energy demand of buildings, it is necessary firstly to cut down the energy requirements to guarantee thermal and lighting comfort and then to meet the residual demand using energy efficient systems. In this sense, glazing elements play an important role in the building envelope to reduce energy demands in terms of heating, cooling and lighting loads. Consequently, the state-of-art of the market of the best performing fenestration products of today and the future research opportunities for the fenestration industry has been widely studied [3-6].

To date, research on STPV modules has been focused, on the one hand, on estimating the energy performance using different commercial simulation software packages [7-11] and, on the other hand, on modeling the heat transfer process and fluid dynamics behavior of ventilated façades [12-19].

Concerning energy performance simulations using existing codes, Bahaj et al. [7] compared the impact of electrochromic glazing, holographic optical elements, aerogel glazing and thin film PV on two highly glazed buildings in arid Middle Eastern climates using TRNSYS. They concluded that glazing integrated thin-film PV solutions are potentially the most promising solution providing an annual cooling load reduction of $31 \%$. The same software was used by Song et al. [8] to calibrate the experimental power output data (DC output) of a commercialized single plate STPV thin-film module modified into a double-glazed one. It was found that the computed 
data was 8.5\% lower than measured output. De Boer and van Helden [9] performed the optimization of the design of STPV modules for building integration taking into account the cooling and heating load, as well as the daylight distribution and the power output of a STPV system integrated in an office room in Madrid. Using different simulation software packages (TRNSYS, WINDOW, Adeline) they concluded that building specific design parameters like orientation, slope of PV surface or internal gain intensity influence the building performance largely than the PV module properties. Miyazaki et al. [10] expounded the effect of thin-film solar cell transmittance and window to wall ratio on the energy consumption of office buildings in terms of heating and cooling loads, daylighting, and electricity production. The simulation was carried out using EnergyPlus and it was found that the total electricity consumption of the building could be reduced by 55\% using optimum STPV windows. The embodied energy payback time (EPBT) of PV modules used as a wall cladding system in a commercial building in United Arab Emirates was calculated by Radhi [11]. In the study was included not only the direct energy output of PV modules but also the reduction in the building cooling load provided by them. The analysis, carried out using Energy-10 software, shows that taking into account the savings in operational energy the EPBT could be reduced from 13 to 3 years approximately.

Regarding the definition of heat transfer models to evaluate the heat gain given by STPV modules in building integrated applications, a significant contribution was provided by Fung and Yang [12]. They presented a one-dimensional heat transfer model and found that the area of solar cells in the PV module has significant effects on the total heat gain, since nearly $70 \%$ of total heat gain can be reduced if the solar cell area ratio is 0.8 . However, other parameters like the solar cell efficiency and the PV module's thickness have only limited influence. The model was validated using a calorimeter box at steady state conditions: a difference of $4.1 \%$ was found between the experimentally measured heat gain and the simulated results. Wong et al. [13] presented power generation, thermal balance and daylight models of roof integrated multicrystalline silicon (mc-Si) STPV and incorporated them into EnergyPlus to carry out overall energy consumption analysis in five climate regions in Japan. It was concluded that with appropriate optimization measures (transparent insulation material and opaque movable insulation depending on the climate region) net energy savings in the range of $3.0-8.7 \%$ are archived relative to the base case of BIPV roof. Another one-dimensional transient model of four different roofs including opaque BIPV was used by Wang et al. [14] to assess the impacts of BIPV on buildings heating and cooling loads in Tianjin, China. It was found that the PV roof with ventilated air-gap is appropriate for the application in summer (low cooling load and high PV conversion efficiency), on the contrary in winter, BIPV of non-ventilated air gap is more effective due to the combination of the low heating-load and high PV electrical output. A mathematical model and computer code were developed by Han et al. [15] to study the heat transfer by natural convection of air in a novel type of a-Si STPV system. They analyzed the effect of cavity air thickness on the overall heat transfer through the window and concluded that the optimum thickness for the air layer was in the range of $60-80 \mathrm{~mm}$. Chow et al. [16] proposed a numerical model of four configurations of a ventilated solar screen window system. The heat flows were analyzed for office hours based on the TMY weather data of Hong Kong. A high saving potential was found in summer using the proposed ventilated window, whereas in winter the benefit of interchanging glass panes was not justified based on the numerical results obtained. Computational Fluid Dynamics simulation was used by Guardo et al. [17] and Gan [18] in order to evaluate the influence of construction and operation parameters of an active transparent facade on solar gain and to assess the effect of the size of air gap between PV modules and the building envelope on the PV performance respectively. According to the first study, the parameters that affect the most the reduction on solar load gain are related with the optical properties of the glass. In the second case, it was found that to reduce the overheating potential, a minimum air gap of $0.12 \mathrm{~m}$ between the PV module and the building envelope would be required. In the same research line Infield et al. [19] proposed a simplified methodology, based on an extension of the U- and g-values, for calculating the thermal impact on building performance of an integrated ventilated PV façade.

Up to now, very limited experimental research has been conducted on the energy performance of STPV modules. One of the studies on this issue was carried out by Park et al. [20] who used an indoor setup (solar simulator) to analyze the variation of the $I-V$ curve of a mc-Si STPV module on depending on the color of the glass on the backside and an outdoor setup to investigate the effects of solar radiation, ambient temperature, and glass used on the temperature and electrical performance of the STPV modules. The results showed that the power decreased about $0.5 \%$ per the $1 \mathrm{C}$ increase of the PV module temperature. It was also found that the property of the glass used for the module affected the PV module temperature and consequently its electrical performance. Another related study was conducted by Li et al. [21]. They experimentally tested an a-Si STPV module to determinate the visible and solar transmittances and the daily mean conversion efficiency. The recorded results were than used to estimate the performance of the façade system applied to a generic reference office building in terms of energy, environmental and economic issues. The electricity reduction represented about $12 \%$ of the annual building demand. Han et al. [22] compared the outdoor performance of a naturally ventilated STPV façade with a conventional clear glass façade. They demonstrated that the ventilated system reduces the possibility of potential overheating problems and that the conversion efficiency of a-Si PV modules slightly decreases from $4.7 \%$ to $4.4 \%$ when its temperature increase about $16^{\circ} \mathrm{C}$. Robinson and Athienitis [23] used an experimental setup to validate the simulated workplane illuminance values in an office with a mc-Si STPV module. It was found that the optimal PV area ratio was $80-90 \%$ for all façade orientations studied from East through South through to West as well as for PV efficiencies of 6-16\%. Furthermore, it was demonstrated that the use of STPV over opaque PV modules can significantly increase the overall net electricity generation of the façade, due to an increased workplane illuminance and thus a reduced lighting load. Chen et al. [24] developed a calorimetric hot box [25] and a solar simulator to measure the Solar Heat Gain Coefficient (SHGC) of five different STPV glazing. They studied the angular effect of the incident solar radiation and of the electrical load on the SHGC values. They found that with an increasing angle of incidence, the SHGC and power generation are reduced significantly (up to $20 \%$ ). On the other hand, connecting electric loads to the STPV module can reduce the SHGC by only 3-6\%.

In summary, various studies into STPV systems have focused on their energy performance based on existing simulation programs. However, global behavior of this type of PV modules could not be correctly represented by any of the commercial simulation tools because they do not implement specific models that properly and simultaneously reflect the singularities of these elements, such as the daylighting and power generation functions. At the same time, current research includes thermal modeling of STPV modules but the predictive models proposed have been validated by limited experimental data.

In this work a methodology for the integral energy performance characterization (thermal, daylighting and electrical behavior) of semi-transparent BIPV elements under real operation conditions is presented. It includes the design principles, construction details and validation of an experimental facility by means of an extensive experimental campaign that has been carried out using four 


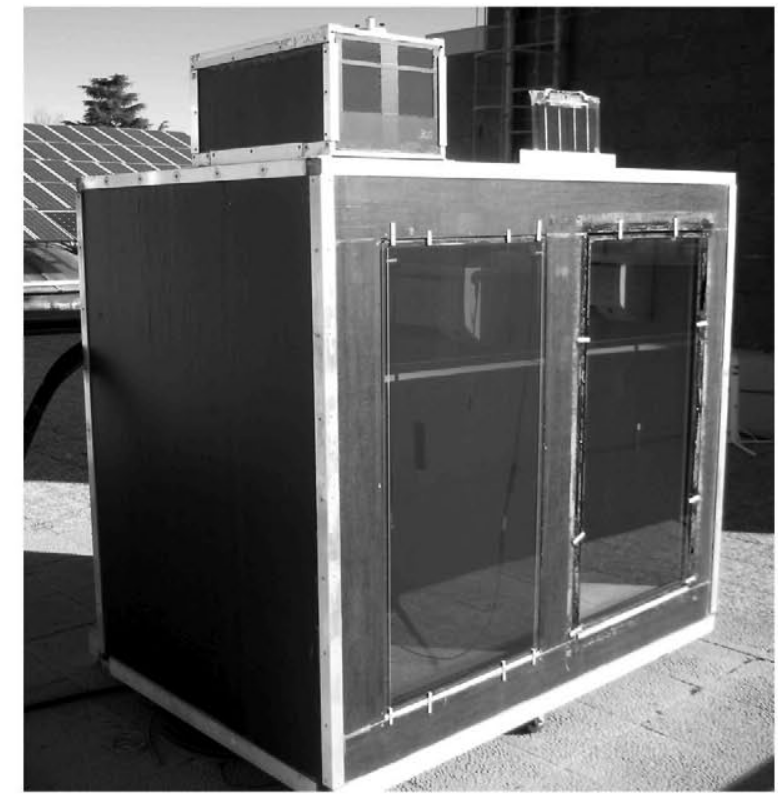

Fig. 1. West and south views of the testing facility. The STPV module is installed on frontal side of the left box. On the frontal face of the right box a code-compliant glass is mounted. On the upper face the scale model used in the daylighting tests and the reference solar cell are installed.

prototypes of a-Si STPV modules developed in collaboration with Soliker, a manufacturer of thin-film PV modules and laminated PV glasses. Each module corresponds to a specific degree of transparency moving from $10 \mathrm{~S}$ (lowest degree, whose visible transmittance value is approximately 0.1 ) to 40 S (highest degree, visible transmittance value of approximately 0.4 ) with the aim of covering a transparency range representative of the market [2].

The article content is as follows. Section 2 describes the methodology and associated experimental testing facility. Section 3 defines the metrics used to describe the integral energy performance of the STPV elements and presents the experimental data and associated statistical analysis. Finally, in Section 4, the main findings of the study are discussed and conclusions are drawn.

\section{Experimental setup}

An experimental testing facility has been designed, developed and built at the Solar Energy Institute of the Technical University of Madrid. It is composed of three independent measurement subsystems for thermal tests, luminous tests and electrical tests that allow carrying out a global analysis under the same ambient conditions. The exterior view of the testing facility is shown in Fig. 1.

\subsection{Thermal tests}

Thermal subsystem involves two highly insulated test boxes. The walls are made of $160 \mathrm{~mm}$ thick extruded polystyrene (XPS) board with phenolic plywood in both side and protective plastic film as the outer layer. This configuration has a thermal transmittance value of approximately $0.2 \mathrm{~W} / \mathrm{m}^{2} \mathrm{~K}$, which guarantees that the thermal flow through the opaque envelope is at least one order of magnitude lower than the thermal flow through the glazed surfaces, considering that the thermal transmittance of the reference glass and STPV modules, calculated according to EN673-2011 standard [26], are $2.9 \mathrm{~W} / \mathrm{m}^{2} \mathrm{~K}$ and $5.7 \mathrm{~W} / \mathrm{m}^{2} \mathrm{~K}$ respectively. Vertically, on the frontal face of one of the boxes the STPV module is installed while on the other box a code-compliant conventional glass is mounted. This configuration allows performing a comparative analysis with the following advantages: it minimizes the effect of measurement errors and simplifies the interpretation of results as the reference element is a conventional, well known product. The frontal faces are south oriented. The emissivity of the reference glass is 0.81 (external side) and 0.84 (internal side). The emissivity of the TCO coated glass used in the STPV modules fabrication is 0.84 (uncoated side) and 0.17 (coated side). The temperature in both chambers is fixed by two independent air conditioning units. The system can operate in cooling mode or in heating mode: in cooling mode the setup temperature is $25^{\circ} \mathrm{C}$ while in heating mode is $23^{\circ} \mathrm{C}$. Temperatures are monitored by 14 thermocouples (T-type, Class $1, \pm 0.5^{\circ} \mathrm{C}$ accuracy) whose locations are shown in Fig. 2.

The aim of the thermal analysis is to investigate the thermal behavior of four different transparency degree STPV modules when they are integrated in a building façade, in comparison with a codecompliant conventional glass. For this purpose cooling and heating loads have been calculated in each test-box. The thermal power extracted from each chamber in cooling mode or supplied in heating mode is calculated using the following equation:

$\dot{\mathrm{Q}}[W]=\dot{m}[\mathrm{~kg} / \mathrm{s}] \cdot c_{p}\left[\mathrm{~J} / \mathrm{kg}^{\circ} \mathrm{C}\right] \cdot\left(T_{\text {out }}\left[{ }^{\circ} \mathrm{C}\right]-T_{\text {in }}\left[{ }^{\circ} \mathrm{C}\right]\right)$

where $\dot{m}$ is the mass flow rate of the air crossing the unit, $c_{p}$ is the specific heat of air at the, moisture and pressure conditions in the box, $T_{\text {out }}$ is the air temperature in the outlet vent section and $T_{\text {in }}$ is the air temperature in the inlet vent section. The calculation was performed each minute using the constant value of the mass flow rate crossing the unit defined in the technical specifications of the air conditioning units, the specific heat of air calculated for the thermo-hygrometric conditions in the boxes, and the air temperature values measured each minute in the inlet (TA 1.6 and TA 2.6) and outlet vent sections (TA 1.7 and TA 2.7). Taking into account that the thermal characterization is carried out measuring the amount of energy necessary to guarantee a constant air temperature inside each box, all the heat transfer mechanisms from inside of the test box to the outside through the STPV modules and reference glass have been considered.

As an example, in Fig. 3 the time series data of outdoor temperature, irradiance and inlet - outlet vent sections temperature difference of one of the STPV modules are shown. In Fig. 3 is possible to notice that the temperature difference distribution is characterized by very low and high values. This distribution is due to the working characteristics of the air conditioning units used to set the temperatures inside the test boxes: high differences between inlet and outlet air temperatures, up to $6^{\circ} \mathrm{C}$, are induced when the units are really working while lower differences, frequently close to $0^{\circ} \mathrm{C}$, when they are in standby mode have been recorded. This causes that the average temperature difference in specific measurement conditions might be comparable to the thermocouples accuracy. In spite of that, if the values in which the influence of the thermocouples accuracy could be relevant are filtered, the average difference of temperature rises up considerably. For instance, if values in Fig. 3 lower than $2^{\circ} \mathrm{C}$ are filtered, the average difference of temperature rises from $1.8^{\circ} \mathrm{C}$ up to $4.1^{\circ} \mathrm{C}(125 \%)$, being the ratio between the thermocouple accuracy and the average difference of temperature equal to $12.2 \%$. It means that even if the average value might be close to the sensors accuracy, due to the discontinuous air conditioning systems working mode, the significant difference of temperature values corresponding to the real thermal energy extracted or supplied are one order of magnitude higher than the sensors accuracy. Through integrating equation (1), daily heating and cooling loads in both test boxes were calculated for 229 days. Using equation 1 two assumptions have been made:

- The first one is that humidity ratio does not change during the cooling process, thus there is not moisture condensation in the unit coil and only sensible heat is extracted by the unit. There are two reasons to assume this simplification. The first is that the 

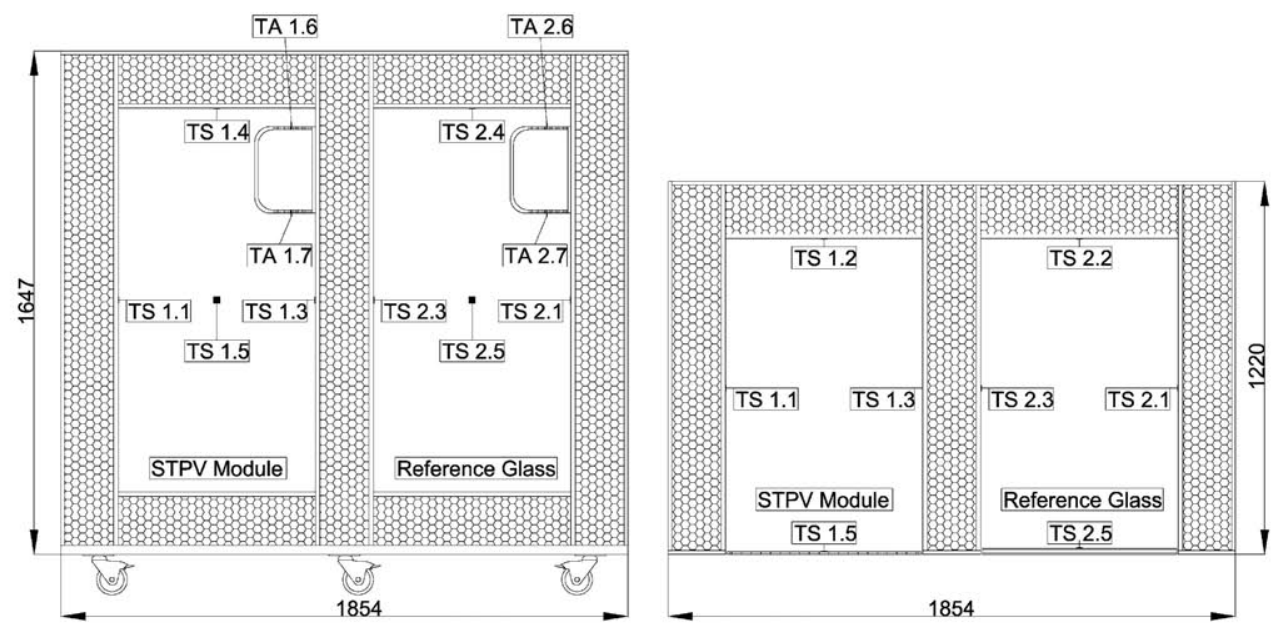

Fig. 2. Dimension of the thermal testing facility and position of the thermocouples. On the left side a vertical section, on the right side a horizontal section. Distances in mm.

cooling unit was working main time with the same volume air, due to the tightness of the box test, so if there was condensation would occur only in the first stage of measurement. The second reason is that in the summertime the average relative humidity in Madrid is only $40 \%$. In any case this supposition was verified experimentally.

- The second assumption done is that the contribution from the water vapor is relatively small on the total value of the specific heat of moist air and consequently may be neglected. This is because the humidity ratio that corresponds to the air internal conditions (dry-bulb temperature of $25^{\circ} \mathrm{C}$ a relative humidity of $40 \%$ and an altitude of $655 \mathrm{~m}$ above sea level approximately) is $0.0085 \mathrm{~kg} / \mathrm{kg}$. So, water component on the overall specific heat of moist air is about $1.5 \%$ and can be ignored.

To determinate real energy flow gone through STPV module and conventional reference glass, minute values of heat flows through the insulated walls ( $160 \mathrm{~mm}$ XPS) were calculated using inner superficial temperatures, exterior air temperature and thermal transmittance of the walls. Flows through the walls were used to correct the loads calculated by equation (1).

\subsection{Daylighting tests}

To perform the daylighting tests a scale model was used whose dimensions duplicate one unit of the reference office originally defined in the European Commission Joule projects REVIS and SWIFT [27] and further refined in the International Energy Agency Solar Heating and Cooling programme Task 25 (Solar assisted air conditioning of buildings), Task 27 (Performance of solar façade components) and Task 31 (Daylight buildings in 21st century) [28]. The 1:10 scale model consists in a light-proof box closed on the frontal side by the STPV element. The element has been shaded partially with a black adhesive foil reproducing the geometry of the façade as shown in Fig. 4.

To carry out the measurements, three luxmeters Mesa Systemtechnik GMBH MS-Lux (2.5\% max deviation) were installed inside the box and one outside. The position of the measurement points inside the box was established dividing the depth of the reference office into three zones and in the center of each one was located a luxmeter at the working plane level $(7.5 \mathrm{~cm}$ above the floor in the 1:10 scale model) as defined in [29]. The dimensions of the test box and the position of the luxmeters are given in Fig. 5 . Measurements of the illuminance values inside and outside of the

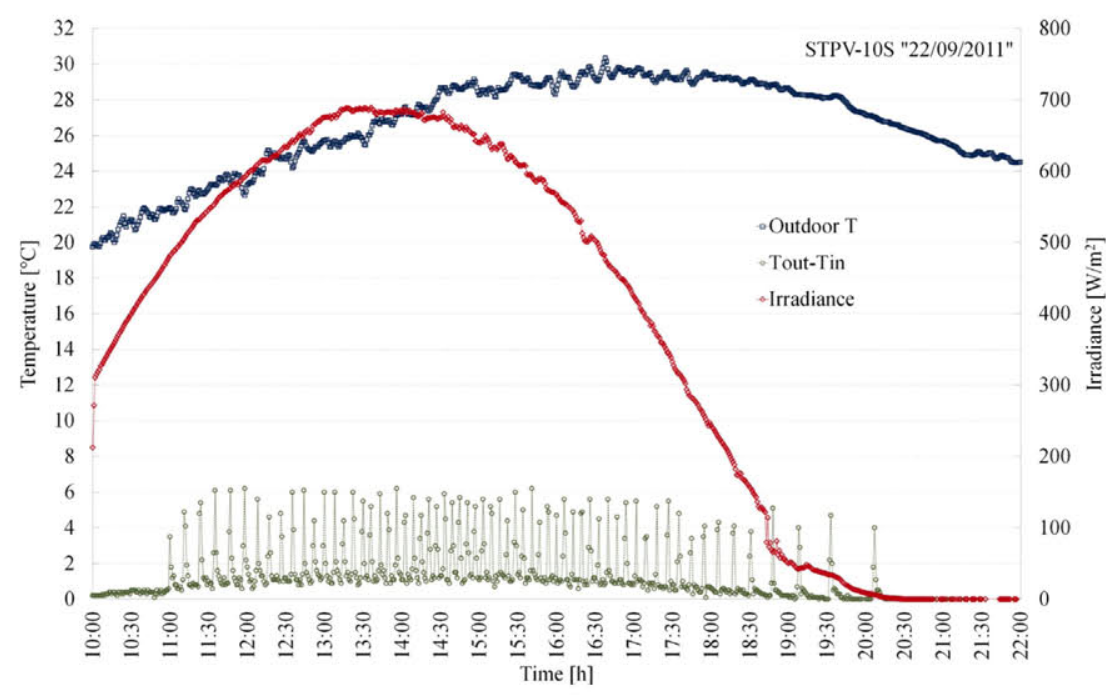

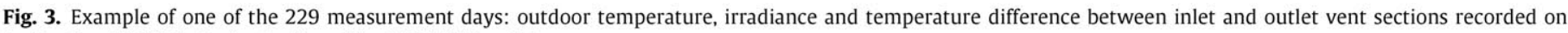
September 22, 2011, during testing of the 10S STPV module. 


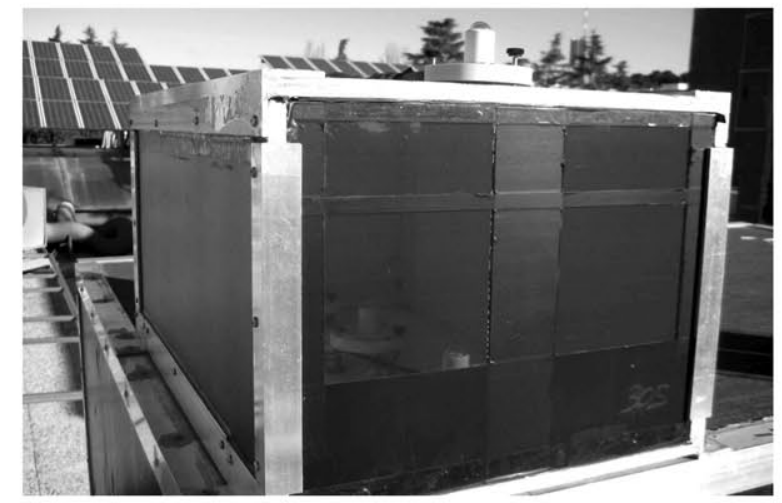

Fig. 4. The $1: 10$ model used in the daylighting tests.

model were carried out both in sunny conditions and in overcast conditions. For this, three typical days were selected and for each of them all the modules were tested measuring indoor and outdoor illuminance values for three times during $15 \mathrm{~min}$ with a sampling period of $5 \mathrm{~s}$. Illuminance values registered under overcast conditions were used to calculate the Daylight Factor (DF) while measures taken under sunny sky conditions, more representative of the local climatology, were used to estimate the daylighting potential provided by modules.

\subsection{Electrical tests}

Electrical tests have been done using a stand-alone configuration. For this purpose a maximum power point tracking (MPPT) battery charger for off-grid PV systems has been used. Monitoring was carried out by measuring every minute the current and the voltage of the PV-module. Irradiance on the vertical plane was measured each minute using a reference solar cell manufactured by Scheuten Solar (calibration accuracy of global irradiance measurements is $2 \%$ ) [30]. Taking into account that the angular behavior of a PV device is mainly defined by the characteristics of the material in contact with the air [31], the similarity between the front glass of the reference solar cell and the STPV modules (low-iron glass, about $3.2 \mathrm{~mm}$ thick in both cases), ensure that the radiation measured with the reference solar cell represents the effective radiation incident on the STPV modules. Short circuit current was used to calculate irradiance and by integrating it daily irradiation was calculated. Daily conversion efficiency was determined by dividing the daily values of electrical output (normalized to unit area of the module) by the effective irradiation incident on the solar cells.
The module efficiency was adjusted taking into account the MPPT efficiency, previously characterized [32].

\section{Results and discussion}

\subsection{Thermal analysis}

To analyze the thermal performance of the STPV modules, two parameters were calculated from the measurements:

- The first parameter, called Heat Gain Coefficient (HGC), is intended to describe the sun-shading performance of STPV modules. Simply, it is the ratio between the daily solar gains transmitted inside the test box through the module (per square meter of module) and the daily irradiation available outside on the vertical plane (where the module is installed).

- The second parameter, called Heat Loss Ratio (HLR), is used to describe the insulating property of the module in comparison to a reference code-compliant double glass. This parameter is the ratio between the night-time heat loss from the STPV test box toward the outside and the simultaneous heat loss from the reference glass test box toward the outside. Obviously, taking into account that the calculated $U$-value of all the single pane STPV modules used in the present analysis is $5.7 \mathrm{~W} / \mathrm{m}^{2} \mathrm{~K}$ approximately (only the degree of transparency changes from one module to another), whereas the $U$-value of reference double glazing is $2.9 \mathrm{~W} / \mathrm{m}^{2} \mathrm{~K}$, the HLR should be constant for all modules and larger than the unit. This parameter allows determining the insulating property of the STPV modules in real operation conditions (transient state), complementing the thermal transmittance information determined in laboratory under steady state conditions [33,34].

\subsubsection{Heat gain - cooling mode from May to October}

The Heat Gain Coefficients (HGC) of the STPV modules and of the glasses were calculated by dividing the daily solar gain by the daily solar irradiation incident on the vertical plane. Taking into account that the solar factor of the reference glass is 0.47 , the next step was to select the days in which the HGC of the glass was included in the range $0.47 \pm 10 \%$. This range was established to avoid the influence of the extreme days on the measurements and to ensure similar test conditions for all tested STPV modules. When this filter is applied, cooling mode data are reduced to 66 days, distributed from the last days of May to the beginning of October. Using the selected data the average HGC value was calculated for each module. The results are shown in Table 1.

To determinate if the differences among the mean HGC values are significant, and thus if the degree of transparency affects the
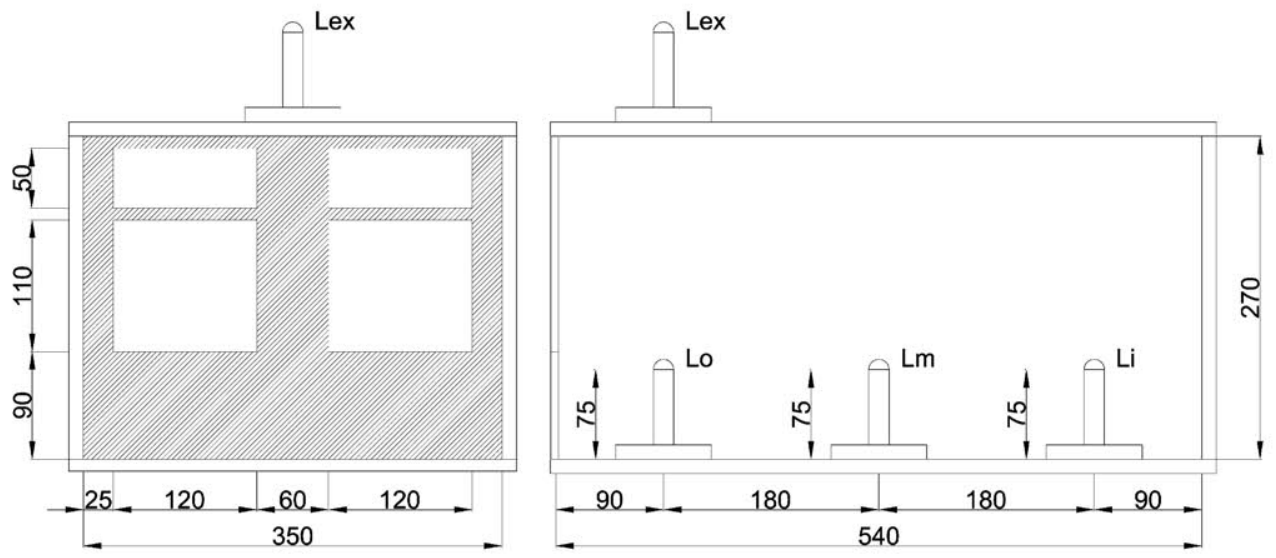

Fig. 5. Dimensions of the scale model and positions of the luxmeters used in the daylighting test. Distances in mm. 
Table 1

Measurement days, values of the mean HGC, standard deviation and coefficient of variation of the four STPV modules.

\begin{tabular}{lcccc}
\hline Module & $10 S$ & $20 S$ & $30 S$ & $40 S$ \\
\hline Days & 18 & 15 & 13 & 20 \\
Mean HGC & 0.655 & 0.660 & 0.679 & 0.734 \\
Standard deviation & 0.050 & 0.073 & 0.074 & 0.037 \\
Coeff. of variation & 0.076 & 0.111 & 0.109 & 0.050 \\
\hline
\end{tabular}

sun-shading performance of the STPV modules, an Analysis of Variance (ANOVA) was carried out [35]. The goal of this analysis is to investigate if the between-sample variance is much larger when compared to the within-sample variance, in other words if the variation among groups is largely caused by the different behavior of the modules, rather than chance variation. Null and alternative hypothesis are:

- $\mathrm{H}_{0}$ : the four STPV modules have the same sun-shading performance during the tests

- $\mathrm{H}_{\mathrm{A}}$ : the four STPV modules have not the same sun-shading performance during the tests.

The results of the ANOVA analysis are shown in Table 2.

According to the results, the probability that the differences of the mean HGC values shown in Table 1 are due to chance is just 0.000279 . We can therefore reject at 95\% confidence (also with $\alpha=0.01$ ) the null hypothesis that the different transparency grade modules have the same sun-shading performance and accept the alternative hypothesis that they have not. The ANOVA does not provide any information about pairwise differences between groups but only demonstrates that there are overall differences among all groups. So, to investigate differences among the performance of the STPV modules, Scheffe's method was used [36]. The first step of Scheffe's method was to calculate the absolute values of pair wise differences between sample means. These differences are displayed in Table 3 . The row headings and the column headings are the different STPV modules. Each entry in the table is the absolute value of the difference between the sample means corresponding to the row and column heading.

The second step of Scheffe's method is to obtain values against which the absolute values of differences between sample means can be compare [36]. Specifically the comparison values are the minimal differences statistically significant at the significance level chosen (in this case $\alpha=0.05$ ). These values are showed in Table 4. As for Table 3, the row headings and the column headings are the different module types.

Each entry in the comparison table was calculated from the following formula:

$M_{i}-M_{j}=\sqrt{(k-1) F_{k-1, n t-k, \alpha} M S E\left(\frac{1}{n_{\infty}}+\frac{1}{n_{j}}\right)}$

where $(k-1)$ is the between samples degrees of freedom, $F_{k-1, n-k, \alpha}$ is the $f$-critic, in other word the $f$-score which defines the rejection region in our hypothesis test (showed in ANOVA table), MSE is the mean square error, $n_{j}$ and $n_{i}$ are the sample sizes, with $i j$ ranging from $10 \mathrm{~S}$ to $40 \mathrm{~S}$.

To identify the statistically significant pair wise differences each of the absolute differences in Table 3 is compared to the corresponding value in Table 4: those absolute differences which are larger are declared as statistically significant at the $\alpha=0.05$ level, and those absolute differences which are smaller are not statistically significant at the $\alpha=0.05$ level. Thus, it can be concluded that the differences of the main Heat Gain Coefficients are statistically significant between:

- the modules $10 \mathrm{~S}$ and $40 \mathrm{~S}$

- the modules $20 \mathrm{~S}$ and $40 \mathrm{~S}$

To check the reliability of the results and to verify that the results have not been affected by variability of operating conditions during the outdoor test of the STPV modules, ANOVA of mean HGC of the reference glass was carried out. The corresponding glass values of the STPV values are resumed in Table 5.

Table 2

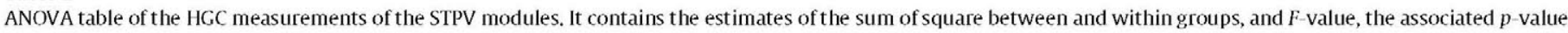
and the $F$ critical value. The probability that the differences we see among the sun-shading performance of the four STPV modules are due to chance alone is $0.0279 \%$.

\begin{tabular}{|c|c|c|c|c|c|c|}
\hline Source of variation & Sum of square & Df & MS & $F$ & $p$-Value & $F \mathrm{cV}$ \\
\hline Between groups & 0.074324 & 3 & 0.024774 & 7.324120 & 0.000279 & 2.752970 \\
\hline Within groups & 0.209721 & 62 & 0.003382 & & & \\
\hline Total & 0.284045 & 65 & & & & \\
\hline
\end{tabular}

Table 3

Absolute values of pair wise differences between sample means of HGC of the four STPV modules.

\begin{tabular}{|c|c|c|c|c|}
\hline & $10 \mathrm{~S}(\mathrm{HGC}=0.655)$ & $20 \mathrm{~S}(\mathrm{HGC}=0.660)$ & $30 \mathrm{~S}(\mathrm{HGC}=0.679)$ & $40 S(\mathrm{HGC}=0.734)$ \\
\hline $10 S(\mathrm{HGC}=0.655)$ & - & 0.006 & 0.024 & 0.079 \\
\hline $20 \mathrm{~S}(\mathrm{HGC}=0.660)$ & 0.006 & - & 0.018 & 0.074 \\
\hline $30 S(\mathrm{HGC}=0.679)$ & 0.024 & 0.018 & - & 0.055 \\
\hline $40 S(H G C=0.734)$ & 0.079 & 0.074 & 0.055 & - \\
\hline
\end{tabular}

Table 4

Minimal differences stat istically significant at $\alpha=0.05$.

\begin{tabular}{|c|c|c|c|c|}
\hline & $10 \mathrm{~S}(\mathrm{HGC}=0.655)$ & $20 \mathrm{~S}(\mathrm{HGC}=0.660)$ & $30 \mathrm{~S}(\mathrm{HGC}=0.679)$ & $40 \mathrm{~S}(\mathrm{HGC}=0.734)$ \\
\hline $10 \mathrm{~S}(\mathrm{HGC}=0.655)$ & - & 0.058 & 0.061 & 0.054 \\
\hline $20 \mathrm{~S}(\mathrm{HGC}=0.660)$ & 0.058 & - & 0.063 & 0.057 \\
\hline $30 S(\mathrm{HGC}=0.679)$ & 0.061 & 0.063 & - & 0.060 \\
\hline $40 S(H G C=0.734)$ & 0.054 & 0.057 & 0.060 & - \\
\hline
\end{tabular}




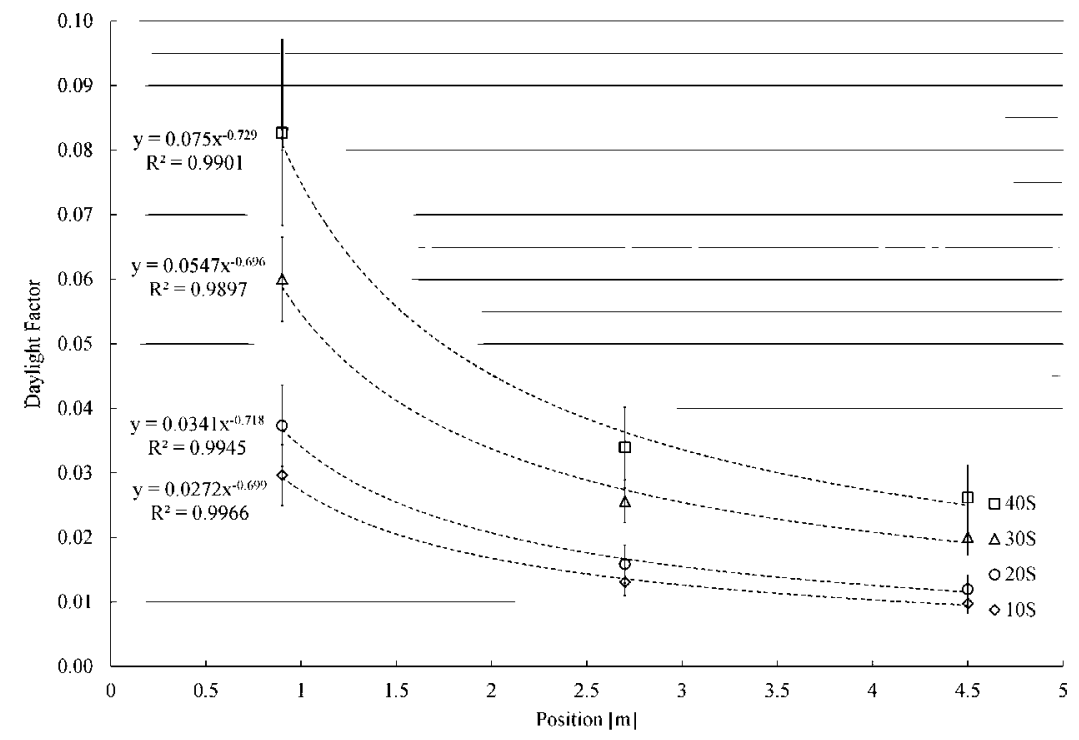

Fig. 6. DF distribution. Error bars represent standard deviation values.

Table 5

Measurement days, values of the mean HGC, standard deviation and coefficient of variation of the reference glass measured simultaneously with the STPV modules indicated in the row headings.

\begin{tabular}{lcccc}
\hline Glass at the same time that & $10 S$ & $20 S$ & $30 S$ & $40 S$ \\
\hline Days & 18 & 15 & 13 & 20 \\
Mean HGC & 0.475 & 0.462 & 0.467 & 0.482 \\
Standard deviation & 0.023 & 0.029 & 0.035 & 0.026 \\
Coeff. of variation & 0.048 & 0.063 & 0.075 & 0.054 \\
\hline
\end{tabular}

In this case, null and alternative hypothesis are:

- $\mathrm{H}_{0}$ : the glass has the same sun-shading performance during the tests

- $\mathrm{H}_{\mathrm{A}}$ : the glass has not the same sun-shading performance during the tests

Table 6 summarizes the results of the ANOVA. As shown, $p$-value is larger than significance level $\alpha=0.05$, we cannot therefore reject the null hypothesis and we can consequently accept that the testing facility performed constantly during the overall test.

\subsubsection{Heat loss - heating mode from November to April}

The Heat Loss Ratio (HLR) was calculated by dividing the nighttime heat loss from the STPV test box toward the outside by the simultaneous heat loss from the reference glass test box toward the outside. Afterwards mean HLR and standard deviation values were calculated for each STPV module. The results are summarized in Table 7.

As expected, the mean HLR is quite constant for all STPV modules and the heat loss through the modules is approximately $40 \%$ larger than the heat loss through the reference glass. Comparing the mean HLR, 1.4 approximately, with the ratio between the thermal transmittance of the STPV modules $\left(5.7 \mathrm{~W} / \mathrm{m}^{2} \mathrm{~K}\right)$ and the $U$-value
Table 7

Measurement days, values of the mean HLR, standard deviation and coefficient of variation of the HLR.

\begin{tabular}{lllll}
\hline Module & $10 S$ & $20 S$ & $30 S$ & $40 S$ \\
\hline Sample & 42 & 69 & 14 & 38 \\
Mean HLR & 1.421 & 1.439 & 1.391 & 1.422 \\
Standard deviation & 0.090 & 0.118 & 0.119 & 0.061 \\
Coeff. of variation & 0.063 & 0.082 & 0.085 & 0.043 \\
\hline
\end{tabular}

of the reference glass $\left(2.9 \mathrm{~W} / \mathrm{m}^{2} \mathrm{~K}\right), 2$ approximately, it can be concluded that in transient state the insulating performance of the STPV modules is better than expected, based on the steady state thermal transmittance value. To determine whether the differences between the mean HLR values are simply due to random error (sampling errors) or whether the variable behavior of the STPV modules causes that the mean in one group differs from the mean in another, an ANOVA analysis was carried out.

As expected, the ANOVA (Table 8) shows no statistically significant differences in the performance of the STPV modules in terms of insulating capacity. The absence of the air layer causes an inadequate thermal behavior in areas characterized by severe winter conditions.

\subsection{Daylighting analysis}

The daylight study was carried out performing relative and absolute analyses. The relative analysis, expressed by the Daylight Factor (DF), the ratio of the internal illuminance to the external illuminance, available simultaneously, allows predicting the percentage of the light available into the room under overcast sky [37]. Absolute values of illuminance under overcast and sunny skies are useful to estimate the illuminance distribution into the room and to evaluate the daylighting performance of STPV modules.

Table 6

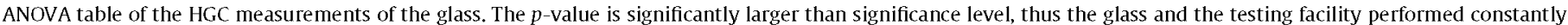
during the tests.

\begin{tabular}{|c|c|c|c|c|c|c|}
\hline Source of variation & Sum of square & $\mathrm{Df}$ & MS & $F$ & $p$-Value & $F C V$ \\
\hline Between groups & 0.004017 & 3 & 0.001339 & 1.729604 & 0.170140 & 2.752970 \\
\hline Within groups & 0.048002 & 62 & 0.000774 & & & \\
\hline Total & 0.052019 & 65 & & & & \\
\hline
\end{tabular}


Table 8

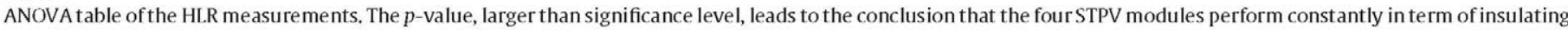
capacity.

\begin{tabular}{|c|c|c|c|c|c|c|}
\hline Source of variation & Sum of square & Df & MS & $F$ & $p$-Value & $F \mathrm{cv}$ \\
\hline Between groups & 0.031467 & 3 & 0.010489 & 1.046164 & 0.373839 & 2.661466 \\
\hline Within groups & 1.594163 & 159 & 0.010026 & & & \\
\hline Total & 1.625630 & 162 & & & & \\
\hline
\end{tabular}

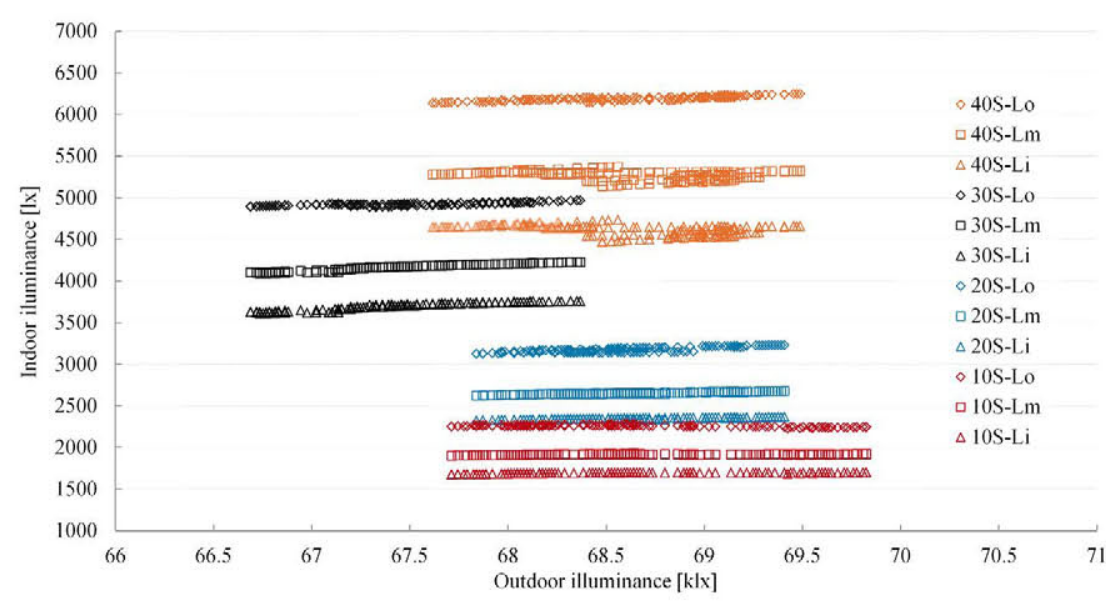

Fig. 7. Illuminance measurements inside (at $L_{\mathrm{i}}, L_{\mathrm{m}}$ and $\mathrm{L}_{\mathrm{o}}$ positions) and outside the scale model performed during a typical summer sunny day.

Table 9

Mean external illuminance values during the illuminance measurements.

\begin{tabular}{|c|c|c|c|c|c|}
\hline & & $10 \mathrm{~S}$ & $20 \mathrm{~S}$ & $30 S$ & $40 \mathrm{~S}$ \\
\hline \multirow{2}{*}{ Typical summer sunny day } & Mean Ext. III. [klx] & 68.56 & 68.57 & 67.39 & 68.62 \\
\hline & Coeff. of Variation & 0.62 & 0.37 & 0.45 & 0.49 \\
\hline \multirow[t]{2}{*}{ Typical winter sunny day } & Mean Ext. III. [kIx] & 68.11 & 67.06 & 69.58 & 64.86 \\
\hline & Coeff, of Variation & 0.07 & 0.66 & 0.06 & 0.32 \\
\hline \multirow{2}{*}{ Typical overcast day } & Mean Ext. Ill. [klx] & 24.29 & 25.93 & 24.85 & 26.12 \\
\hline & Coeff. of Variation & 5.96 & 6.99 & 6.95 & 6.20 \\
\hline
\end{tabular}

\subsubsection{Daylight factor}

Fig. 6 represents the distribution of the mean DF calculated respectively at $0.9 \mathrm{~m}, 2.7 \mathrm{~m}$ and $4.5 \mathrm{~m}$ from the module under test. Error bars represent standard deviation values. To calculate the DF, illuminance values were registered under overcast conditions during $15 \mathrm{~min}$ with a sampling period of $5 \mathrm{~s}$. The measurements were performed rotating the modules and were repeated three times for each module in order to ensure similar conditions of illuminance. A total of 2160 values were processed. It can be seen that at $0.9 \mathrm{~m}$ mean DF ranges between $8.3 \%(40 \mathrm{~S})$ and $3.0 \%(10 \mathrm{~S})$ and at $4.5 \mathrm{~m} \mathrm{DF}$ values range between $2.6 \%$ and $1.0 \%$ respectively. $20 \mathrm{~S}$ and $30 \mathrm{~S}$ modules provide intermediate DF values with 20 S very closed to $10 \mathrm{~S}$. En each case, DF distribution can be approximated with a power function whose coefficients are shown in the figure.

As can be seen in Fig. 6 the statistical dispersion decreases from the next to window zone to the internal zone and also decreases as the transparency degree moves from high (40S) to low (10S). The $2 \%$ value of the DF, frequently considered as a minimum value [38],

Table 10

Measurement days, mean, standard deviation and coefficient of variation of the daily conversion efficiency.

\begin{tabular}{lcccc}
\hline Module & $10 S$ & $20 S$ & $30 S$ & $40 S$ \\
\hline Days & 37 & 105 & 54 & 91 \\
Mean efficiency [\%] & 2.932 & 2.879 & 3.203 & 2.095 \\
SD [\%] & 0.486 & 0.356 & 0.216 & 0.136 \\
Coeff. of variation & 0.166 & 0.124 & 0.067 & 0.065 \\
\hline
\end{tabular}

is reached at $2.7 \mathrm{~m}$ and $4.5 \mathrm{~m}$ points only by $30 \mathrm{~S}$ and $40 \mathrm{~S}$ modules, while at 0.9 point is exceeded by all STPV modules.

\subsubsection{Illuminance}

In different days, illuminance values were registered during 15 min with a sampling period of $5 \mathrm{~s}$. With the purpose of covering a wide range of lighting conditions, three cases were analyzed:

a. Sunny sky with high exterior illuminance and no direct sunlight over internal luxmeters (typical summer sunny day);

b. Sunny sky with high exterior illuminance and direct sunlight over internal luxmeter $L_{0}$ (Fig. 5) at $0.9 \mathrm{~m}$ (typical winter sunny day);

c. Overcast sky with low exterior illuminance (typical overcast day).

In Fig. 7 the illuminance values registered inside and outside the scale model are shown, corresponding to the first case described

Table 11

Measurement days, daily mean, standard deviation and coefficient of variation of the irradiation.

\begin{tabular}{lcccc}
\hline Module & $10 S$ & $20 S$ & $30 S$ & $40 S$ \\
\hline Days & 35 & 105 & 54 & 91 \\
Mean daily Irr. [Wh $\left./ \mathrm{m}^{2}\right]$ & 3418 & 3156 & 3154 & 3290 \\
SD [Wh/ $\left.\mathrm{m}^{2}\right]$ & 1547 & 1300 & 1421 & 1029 \\
Coeff. of variation & 0.453 & 0.412 & 0.450 & 0.313
\end{tabular}




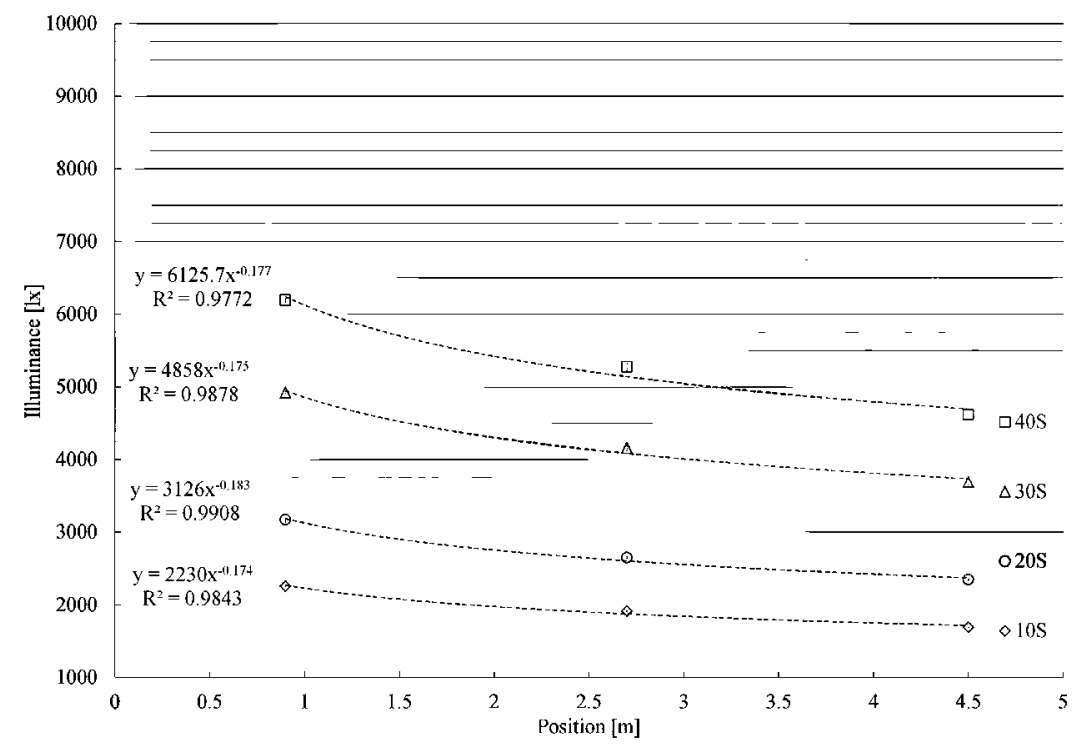

Fig. 8. Illuminance distribution with high exterior illuminance and no direct sunlight over internal luxmeters (typical summer day).

above, with high exterior illuminance and no direct sunlight over internal luxmeters. The outdoor illuminance is quite constant (compare with Table 9) and the indoor illuminance is dominated by the degree of transparency of the STPV modules. The illuminance conditions during the daylighting tests are summarized in Table 9.

Illuminance distributions in the cases analyzed are shown in Figs. $8-10$.

\section{a. Typical summer sunny day.}

Under sunny sky conditions and with no direct sunlight falling over any luxmeter, the illuminance distribution can be well approximated (coefficient of determination $R^{2}>0.977$ in any case) with a power function $y=a x^{b}$ and the curves have almost the same trend (the $b$ coefficient of the power functions is quite constant). However, results show that a module of low degree of transparency provides lower illuminance values but a more uniform distribution of illuminance than a module of high transparency. Also, it can be noticed that the largest difference between illuminance curves occurs between $20 \mathrm{~S}$ and $30 \mathrm{~S}$ modules while between $10 \mathrm{~S}$ and $20 \mathrm{~S}$, as well as between $30 \mathrm{~S}$ and
40S, the differences of illuminance are smaller. Accordingly, the behavior of the modules can be divided into two groups that can be defined as low grade of transparency (10S-20S) and high grade of transparency (30S-40S). In any case, under such conditions, internal illuminance values are not useful because they are larger than $2000 \mathrm{~lx}$ [39] (apart from $10 \mathrm{~S}$ in $0.27 \mathrm{~m}$ and $0.45 \mathrm{~m}$ points) and visual discomfort may be generated.

b. Typical winter sunny day

In the second case (Fig. 9) the direct sunlight hits over the luxmeter at point $0.9 \mathrm{~m}$ This causes that illuminance values in this position shoot up and exceed $9 \mathrm{klx}$ for all the modules with very similar values for modules $20 \mathrm{~S} 30 \mathrm{~S}$ and $40 \mathrm{~S}(9.6 \mathrm{klx})$ and a quite lower illuminance value for $10 \mathrm{~S}$ module $(9.2 \mathrm{klx})$. In this case, a power function does not fit the experimental data as well as in the previous case. An interesting finding is that in this case illuminance values at $2.7 \mathrm{~m}$ and $4.5 \mathrm{~m}$ are lower than in the previous case but, as well as the first case, illuminance distribution is more uniform in low grade of transparency modules. This is particularly noticeable comparing illuminance values at $2.7 \mathrm{~m}$ and $4.5 \mathrm{~m}$ points. The illuminance drop moving from $2.7 \mathrm{~m}$ point to

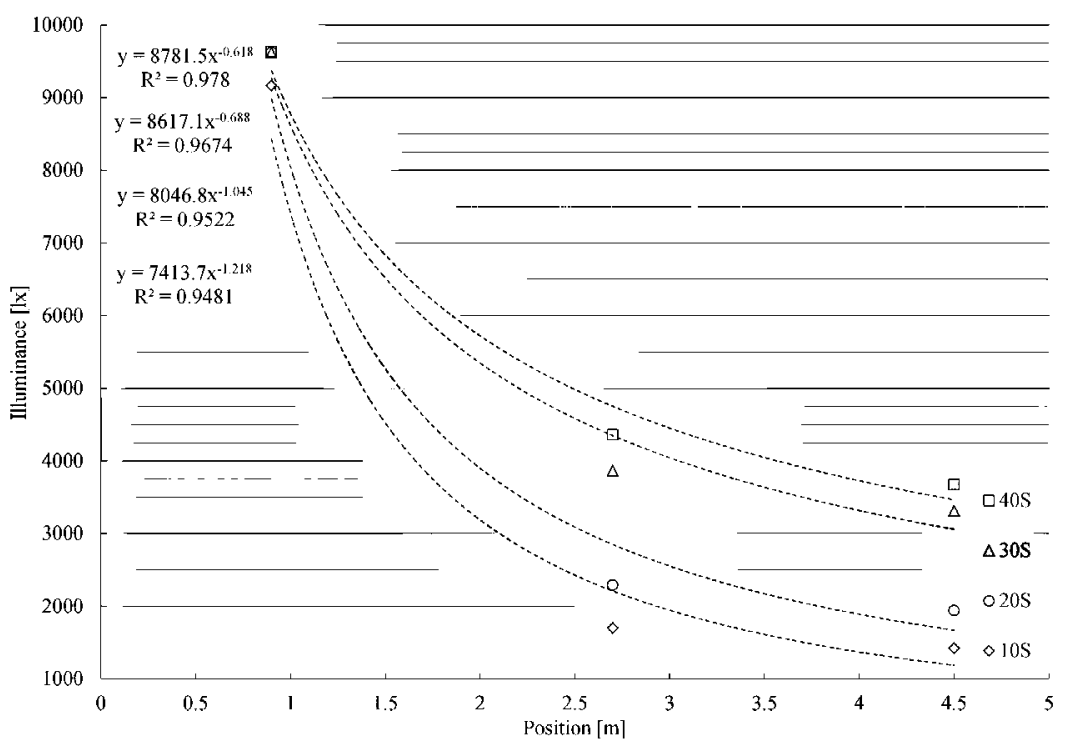

Fig. 9. Illuminance distribution with high exterior illuminance and direct sunlight over close to window $L_{0}$ luxmeter (typical winter day). 


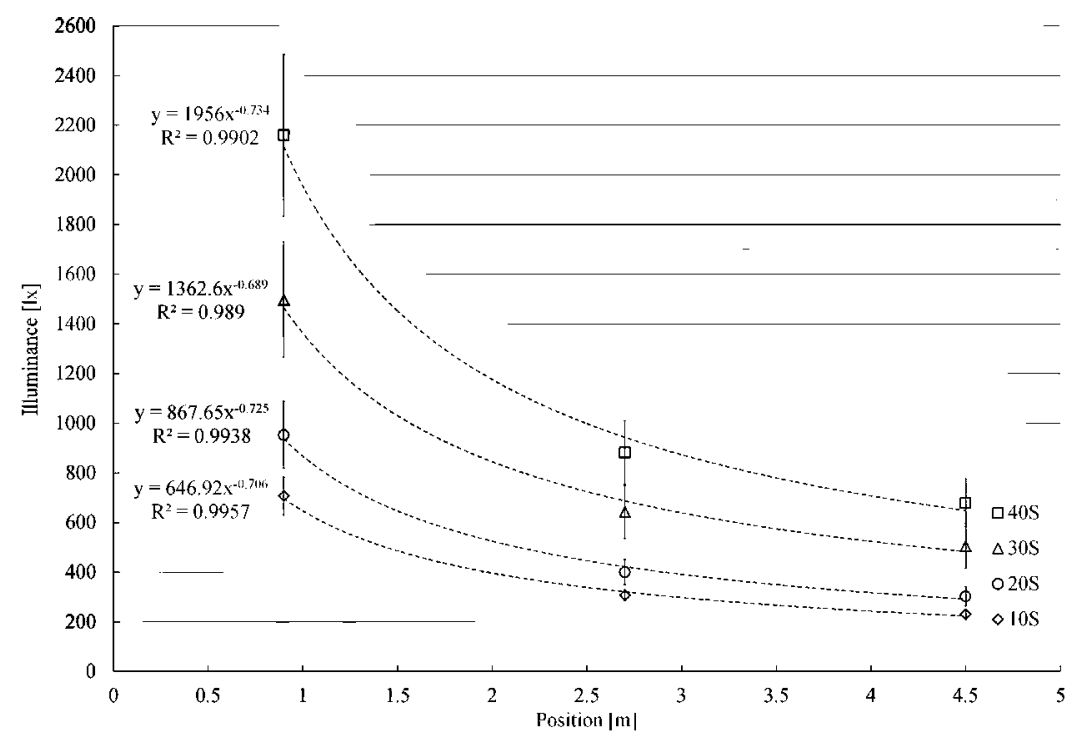

Fig. 10. Illuminance distribution under overcast sky conditions.

Table 12

ANOVA table of the measurements of daily irradiation.

\begin{tabular}{|c|c|c|c|c|c|c|}
\hline Source of variation & Sum of square & Df & MS & $F$ & $p$-Value & $F \mathrm{CV}$ \\
\hline Between groups & 2450455.014 & 3 & 816818.338 & 0.500 & 0.683 & 2.637 \\
\hline Within groups & 459450648.371 & 281 & 1635055.688 & & & \\
\hline Total & 461901103.385 & 284 & & & & \\
\hline
\end{tabular}

Table 13

Measurement days, daily mean, standard deviation and coefficient of variation of the superficial temperature.

\begin{tabular}{lllll}
\hline Module & $10 \mathrm{~S}$ & $20 \mathrm{~S}$ & $30 \mathrm{~S}$ & $40 \mathrm{~S}$ \\
\hline Sample & 35 & 105 & 54 & 91 \\
Mean daily sup. temp. $\left[{ }^{\circ} \mathrm{C}\right]$ & 28.4 & 27.9 & 27.9 & 28.7 \\
Standard deviation $\left[{ }^{\circ} \mathrm{C}\right]$ & 6.657 & 6.686 & 4.919 & 4.890 \\
Coeff. of variation & 0.234 & 0.240 & 0.176 & 0.170 \\
\hline
\end{tabular}

$4.5 \mathrm{~m}$ point is larger for high grade of transparency STPV modules than for those with low grade of transparency. 10S module provides useful illuminance values ( smaller than $2000 \mathrm{~lx}$ ) in sections $2.7 \mathrm{~m}$ and $4.5 \mathrm{~m}, 20 \mathrm{~S}$ only in section $4.5 \mathrm{~m}$ and all others module provide too high illuminance values in any section. This suggests that this configuration of STPV modules to replace glasses in building façades does not solve the glare problem under sunny sky conditions.

c. Typical overcast day.

The results of the measurements carried out under overcast sky conditions are shown in Fig. 10. In this case, all the modules provide useful illuminance values in any section with the exception of $40 \mathrm{~S}$ module at $0.9 \mathrm{~m}$. Moreover, the reduction of the illuminance value moving from window to the internal zone is more pronounced for more transparent modules.

\subsection{Electrical analysis}

To carry out the electrical analysis the modules were monitored under real operation conditions, that is, working at maximum power point. The daily efficiency was calculated by dividing daily electrical energy output per square meter by the irradiation incident on the vertical plane. Results are summarized in Table 10. As expected, the efficiency decreases with increasing transparency degree, except for the module 305 which has provided the highest value. In any case, the mean conversion efficiency values range between $2.1 \%(40 \mathrm{~S})$ and $3.2 \%(30 \mathrm{~S})$.

To prove the homogeneity of the climatic conditions during the test, both in terms of daily irradiation and daily average surface temperature of the modules, mean daily irradiation and mean daily superficial temperature were calculated for each module. In Table 11 are shown results about daily irradiation on the vertical plane. Even if there is some variation between the average values (during $10 \mathrm{~S}$ test mean daily irradiation was $3417.8 \mathrm{Wh} / \mathrm{m}^{2}$ while during $30 \mathrm{~S}$ test mean daily irradiation was $3153.8 \mathrm{Wh} / \mathrm{m}^{2}$ ) ANOVA (Table 12) demonstrates that there are not overall differences among all groups, so we can consider that the irradiation conditions were uniform during the test of the four modules.

The same test was performed to investigate the uniformity of the operational temperature conditions of the modules. Table 13 shows the main daily superficial temperature of the modules during test. The mean values and standard deviation are similar and performing ANOVA (Table 14) we can conclude that the four population means

Table 14

ANOVA table of the superficial temperature.

\begin{tabular}{|c|c|c|c|c|c|c|}
\hline Source of variation & Sum of Square & Df & MS & $F$ & $p$-Value & $F C V$ \\
\hline Between groups & 32.733 & 3 & 10.911 & 0.319 & 0.812 & 2.637 \\
\hline Within groups & 9679.445 & 283 & 34.203 & & & \\
\hline Total & 9712.178 & 286 & & & & \\
\hline
\end{tabular}


are equal, i.e., operational temperature conditions were uniform during the test.

\section{Conclusions}

In this study, a methodology has been developed for the integral energy characterization of STPV modules, covering thermal, daylighting and electrical performance. The remarkable findings of this work are listed below:

- The methodology proposed allows simultaneous characterization of the global energy performance of semi-transparent photovoltaic modules (STPV) under real operation conditions. The associated testing facility has been operated continuously during one year without any problem, showing the quality of the design, its reliability and the capability to be used in future to carry out complementary studies based on optimized elements.

- Validation of the methodology and associated experimental setup has been done by means of an experimental campaign of one year carried out with four prototypes of a-Si STPV modules covering a transparency range representative of the current market (visible transmittances between 0.1 and 0.4). All tested BIPV elements have substantially larger Heat Gain Coefficients (HGC) than the reference glass. HGC of the modules ranges between 0.65 and 0.73 whereas HGC of the reference glass (double glass compliant with the Spanish Technical Building Code) ranges between 0.46 and 0.48. ANOVA and Scheffe's method show that the differences of the main HGC are statistically significant between the modules with lowest and highest transparency degree (10S and 40S respectively). This was not the case with modules of intermediate transparency degree (20S and 30S, with visual transmittances of approximately 0.2 and 0.3 respectively), where the analysis shows no statistically significant differences in the HGC values. ANOVA of mean HGC of the reference glass shows that results have not been affected by the variability of operating conditions during the outdoor test and that the measurement setup performed regularly. The HGC of the $40 \mathrm{~S}$ module $(0.734)$ is $12.1 \%$ larger than HGC of $10 \mathrm{~S}(0.655)$ and $11.2 \%$ larger than HGC of $20 \mathrm{~S}$ (0.660). These data suggest that the solar protection function provided by this configuration of the STPV modules is in general not satisfactory. An optimization of the prototypes will be carried out to avoid overheating problem in summer conditions, the results of which will be presented in future work.

- The Heat Loss Ratio (HLR), or night time heat losses, relative to those of the reference glass, calculated by dividing the night-time heat loss from the STPV test box toward the outside by the heat loss from the reference glass test box toward the outside at the same time, is constant for all modules (no statistically significant differences in the performance of the modules in terms of insulating capacity has been found) and assumes a value of 1.4. Heat loss through the STPV modules measured (transient state) is approximately $40 \%$ larger than heat loss through the reference glass, whereas the thermal transmittance of the STPV modules ( $U$ value) is approximately twice the thermal transmittance of the reference glass. This result demonstrates that a characterization in real operation conditions is necessary to describe and predict the actual performance of STPV modules. As expected, single pane prototypes tested are not appropriate to be used as insulating layer in the building envelope because in this case heating load would be extremely high to compensate for the heat losses. An improvement of the insulating property will be implemented in optimized prototypes.

- Daylight Factor (DF), calculated under overcast sky conditions, presents a potential function distribution. In the close to window zone DF ranges between $3 \%(10 \mathrm{~S})$ and $8.3 \%(40 \mathrm{~S})$ whereas in the furthest zone from the window DF ranges between $1 \%(10 \mathrm{~S})$ and $2.6 \%(40 S)$. At any measurement point, the $D F$ reduction moving from the higher grade of transparency to the next lower grade is about $25 \%$ from 40 S to 30 S, $39 \%$ from 30 S to 20 S and $18 \%$ from $20 \mathrm{~S}$ to $10 \mathrm{~S}$.

- Indoor illuminance values registered on the work plane under sunny conditions in the close to window zone vary between $2257 \mathrm{~lx}(10 \mathrm{~S})$ and $6191 \mathrm{~lx}(40 \mathrm{~S})$. In the most internal zone illuminance values vary between $1692 \mathrm{~lx}(10 \mathrm{~S})$ and $4616 \mathrm{~lx}(40 \mathrm{~S})$. At any measurement point, the illuminance reduction moving from the higher grade of transparency to the next lower grade is about $20 \%$ from 40 S to 30 S, $36 \%$ from 30 S to 20 S and $28 \%$ from 20 S to $10 \mathrm{~S}$. When direct sunlight hits over the close to window luxmeter, illuminance values in this position shoot up and exceed $9 \mathrm{klx}$ for all the modules. When this happens, in the intermediate and internal positions illuminance values are lower than in the previous case, with an approximately mean reduction of $12 \%$ and $16 \%$ respectively. In any case, PV elements with low degree of transparency provide a more uniform distribution of the illuminance. Although in this study several cases of lighting conditions have been studied, to complete the daylighting analysis and translate the findings obtained into lighting saving potential, future analysis should be carried out. In particular, a parametric Climate-Based Daylight Analysis should be performed to fully estimate the performance of the STPV modules under all the naturally occurring variations in daylight availability.

- The electrical analysis shows that, in general, the mean daily conversion efficiency of the STPV modules under real operation conditions decreases with increasing transparency degree. The homogeneity of the irradiation and temperature conditions during the outdoor measurement is proved by ANOVA test. Unexpectedly, the highest mean efficiency is provided by 30 S module (3.2\%) and only for this module the energy-based efficiency, here calculated, matches the power-based STC efficiency declared in the technical specifications. Low transparency degree modules (10S and 20S) provide very similar efficiencies being the reduction of the mean efficiency between 10 S and 20 S less than $2 \%$. Obviously, the results of this analysis, carried out on four modules only, cannot be extrapolated but the findings of this study suggest that the transparency degree is not the most determining factor for the electrical performance of the module. Likely, this parameter does not affect the efficiencies of the a-Si STPV modules more than other factors like, for instance, the manufacturing quality.

- In conclusion, a methodology to realistically assess the global performance of STPV modules has been proposed and validated. Characterization of these elements in real operation conditions is necessary to promote an energetically efficient integration in buildings envelope, following up on the requirements of the regulations focused to reduce the energy use in buildings, like the directive 2010/31/EU of the European Parliament on the energy efficiency of buildings.

\section{Acknowledgment}

The authors would like to thank the support of Soliker, particularly in the manufacturing of the prototypes used.

\section{References}

[1] M. Pagliaro, R. Ciriminna, G. Palmisano, BIPV: merging the photovoltaic with the construction industry, Progress in Photovoltaics: Research and Applications 18 (1) (2010) 61-72.

[2] B. Petter Jelle, C. Breivik, H. Drolsum Røkenes, Building integrated photovoltaic products: a state-of-the-art review and future research opportunities, Solar Energy Materials and Solar Cells 100 (2012) 69-96. 
[3] B.P. Jelle, A. Hynd, A. Gustavsen, D. Arasteh, H. Goudey, R. Hart, Fenestration of today and tomorrow: a state-of-the-art review and future research opportunities, Solar Energy Materials and Solar Cells 96 (0) (2012) 1-28.

[4] T, Gil-Lopez, C. Gimenez-Molina, Influence of double glazing with a circulating water chamber on the thermal energy savings in buildings, Energy and Buildings $56(0)(2013) 56-65$.

[5] T.-t. Chow, C. Li, Z. Lin, Innovative solar windows for cooling-demand climate, Solar Energy Materials and Solar Cells 94 (2) (2010) 212-220.

[6] T.-T. Chow, Z. Qiu, C. Li, Potential application of "see-through" solar cells in ventilated glazing in Hong Kong, Solar Energy Materials and Solar Cells 93 (2) (2009) $230-238$.

[7] A.S. Bahaj, P.A.B. James, M.F. Jentsch, Potential of emerging glazing technologies for highly glazed buildings in hot arid climates, Energy and Buildings 40 (5) (2008) 720-731.

[8] J.-H. Song, Y.-S. An, S.-G. Kim, S.-J. Lee, J.-H. Yoon, Y.-K. Choung, Power output analysis of transparent thin-film module in building integrated photovoltaic system (BIPV), Energy and Buildings 40 (11) (2008) 2067-2075.

[9] B.J. de Boer, W.G.J. van Helden, PV-Mobi: PV modules optimized for building integration, in: 9th Internacional Conference on Solar Energy in High Latitudes, Northsun, Leiden, The Netherlands, 2001.

[10] T. Miyazaki, A. Akisawa, T. Kashiwagi, Energy savings of office buildings by the use of semi-transparent solar cells for windows, Renewable Energy 30 (3) (2005) 281-304.

[11] H. Radhi, Energy analysis of façade-integrated photovoltaic systems ap plied to UAE commercial buildings, Solar Energy 84 (12) (2010) 2009-2021.

[12] T.Y.Y. Fung, H. Yang, Study on thermal performance of semi-transparent building-integrated photovoltaic glazings, Energy and Buildings 40 (3) (2008) 341-350.

[13] P.W. Wong, Y. Shimoda, M. Nonaka, M. Inoue, M. Mizuno, Semi-transparent PV: thermal performance, power generation, daylight modelling and energy saving potential in a residential application, Renewable Energy 33 (5) (2008) 1024-1036.

[14] Y. Wang, W. Tian, J. Ren, L. Zhu, Q. Wang, Influence of a building's integratedphotovoltaics on heating and cooling loads, Applied Energy 83 (9) (2006) 989-1003.

[15] J. Han, L, Lu, H. Yang, Thermal behavior of a novel type see-through glazing system with integrated PV cells, Building and Environment 44 (10) (2009) $2129-2136$

[16] T.T. Chow, Z. Lin, W. He, A.L.S. Chan, K.F. Fong, Use of ventilated solar screen window in warm climate, Applied Thermal Engineering 26 (16) (2006) 1910-1918.

[17] A. Guardo, M. Coussirat, E. Egusquiza, P. Alavedra, R. Castilla, A CFD approach to evaluate the influence of construction and operation parameters on the performance of Active Transparent Façades in Mediterranean climates, Energy and Buildings 41 (5) (2009) 534-542.

[18] G. Gan, Effect of air gap on the performance of building-integrated photovoltaics, Energy 34 (7) (2009) 913-921.

[19] D. Infield, U. Eicker, V. Fux, L. Mei, J. Schumacher, A simplified approach to thermal performance calculation for building integrated mechanically ventilated PV facades, Building and Environment 41 (7) (2006) 893-901.
[20] K.E. Park, G.H. Kang, H.I. Kim, G.J. Yu, J.T. Kim, Analysis of thermal and electrical performance of semi-transparent photovoltaic (PV) module, Energy 35 (6) (2010) 2681-2687.

[21] D.H.W. Li, T.N.T. Lam, W.W.H. Chan, A.H.L. Mak, Energy and cost analysis of semi-transparent photovoltaic in office buildings, Applied Energy 86 (5) (2009) $722-729$.

[22] J. Han, L. Lu, J. Peng, H. Yang, Performance of ventilated double-sided PV façade compared with conventional clear glass façade, Energy and Buildings $56(0)$ (2013) 204-209.

[23] L. Robinson, A. Athienitis, Design methodology for optimization of electricity generation and daylight utilization for facade with semi-transparent photo voltaics, in: 11th International IBPSA Conference - Building Simulation 2009, Glasgow, 2009, pp. 811-818.

[24] F. Chen, S.K. Wittkopf, P. Khai Ng, H. Du, Solar heat gain coefficient measurement of semi-transparent photovoltaic modules with indoor calorimetric hot box and solar simulator, Energy and Buildings 53 (0) (2012) 74-84.

[25] F. Chen, S.K. Wittkopf, Summer condition thermal transmittance measurement of fenestration systems using calorimetric hot box, Energy and Buildings $53(0)$ (2012) 47-56.

[26] E.C.f. Standardization Glass in building. Determination of thermal transmittance (U value). Calculation method, in: EN 673, 2011, p. 2011.

[27] H.A.L. van Dijk, The European project revis, daylighting products with redirecting visual properties, in: NorthSun Conference, Leiden, Netherlands, 2001.

[28] H.A.L. van Dijk, Reference office for thermal, solar and lighting calculations, IEA Task 27, performance of solar facade components, in: TNO Building and Construction Research, Delft, The Netherlands, 2001.

[29] M.R. Atif, J.A. Love, P. Littlefair, Daylighting monitoring protocols and proce dures for buildings, in: A report of IEA Task 21/Annex 29 Daylight in Buildings, International Energy Association, 1997.

[30] I.E. Commission, Photovoltaic devices - part 2: requirements for reference solar devices, in: IEC 60904-2:2007, IEC, Switzerland, 2007.

[31] N. Martin, J.M. Ruiz, Calculation of the PV modules angular losses under field conditions by means of an analytical model, Solar Energy Materials and Solar Cells 70 (1) (2001) 25-38.

[32] M. Camino-Villacorta, M.A. Egido-Aguilera, P. Díaz, Test procedures for maximum power point tracking charge controllers characterization, Progress in Photovoltaics: Research and Applications 20 (3) (2012) 310-320.

[33] E.C.f. Standardization Glass in building. Determination of thermal transmit tance (U value). Heat flow meter method, in: EN 675, 2011, p. 2011.

[34] E.C.f. Standardization Glass in building. Determination of thermal transmittance (U value). Guarded hot plate method, EN 674, 2011, p. 2011

[35] N.R. Draper, H. Smith, Applied Regression Analysis, Wiley, New York, 1998.

[36] M.H. Kutner, C.J. Nachtsheim, J. Neter, W. Li, Applied Linear Statistical Models, WCB McGraw-Hill/lrwin, New York, 2005.

[37] T. Muneer, C. Gueymard, H. Kambezidis, 3 - Hourly Horizontal Irradiation and Illuminance, in: Solar Radiation and Daylight Models, second ed., ButterworthHeinemann, Oxford, 2004, pp. 61-142.

[38] J. Mardaljevic, L. Heschong, E. Lee, Daylight metrics and energy savings, Lighting Research and Technology 41 (3) (2009) 261-283.

[39] A. Nabil, J. Mardaljevic, Useful daylight illuminances: a replacement for daylight factors, Energy and Buildings 38 (7) (2006) 905-913. 